\title{
Inhibition of HER2-integrin signaling by Cucurbitacin B leads to in vitro and in vivo breast tumor growth suppression
}

\author{
Parul Gupta ${ }^{1}$ and Sanjay K. Srivastava ${ }^{1,2}$ \\ ${ }^{1}$ Department of Biomedical Sciences and Cancer Biology Center, Texas Tech University Health Sciences Center, Amarillo, \\ TX, USA. \\ ${ }^{2}$ Cancer Preventive Material Development Research Center, College of Korean Medicine, Department of Pathology, Kyunghee \\ University, 1 Hoegi-dong, Dongdaemun-ku, Seoul, South Korea
}

Correspondence to: Sanjay K. Srivastava, email: sanjay.srivastava@ttuhsc.edu

Keywords: Breast cancer, in vivo, ITGB4, ITGA6, Cucurbitacin B

Received: December 25, 2013 Accepted: February 24, $2014 \quad$ Published: February 25, 2014

This is an open-access article distributed under the terms of the Creative Commons Attribution License, which permits unrestricted use, distribution, and reproduction in any medium, provided the original author and source are credited.

\section{ABSTRACT:}

HER2, an oncogenic receptor is overexpressed in about $25-30 \%$ of breast cancer patients. HER2 has been shown to play role in tumor promotion by having cross-talk with multiple oncogenic pathways in cancer cells. Our results show that Cucurbitacin B (CuB), a triterpenoid steroidal compound inhibited the growth of various breast cancer cells with an IC50 ranging from 18-50nM after 48 and $72 \mathrm{~h}$ of treatment. Our study also revealed the significant inhibitory effects of CUB on HER2 and integrin signaling in breast cancer. Notably, CuB inhibited ITGA6 and ITGB4 (integrin a6 \& integrin $\beta 4$ ), which are overexpressed in breast cancer. Furthermore, CuB also induced the expression of major ITGB1and ITGB3, which are known to cause integrinmediated cell death. In addition, we observed that TGF $\beta$ treatment resulted in the increased association of HER2 with ITGA6 and this association was inhibited by CuB treatment. Efficacy of CuB was tested in vivo using two different orthotopic models of breast cancer. MDA-MB-231 and 4T-1 cells were injected orthotopically in the mammary fat pad of female athymic nude mice or BALB/c mice respectively. Our results showed that CuB administration inhibited MDA-MB-231 orthotopic tumors by $55 \%$, and $4 \mathrm{~T}-1$ tumors by $40 \%$. The $4 \mathrm{~T}-1$ cells represent stage IV breast cancer and form very aggressive tumors. CuB mediated breast tumor growth suppression was associated with the inhibition of HER2/integrin signaling. Our results suggest novel targets of CuB in breast cancer in vitro and in vivo.

\section{INTRODUCTION}

Breast cancer is the most commonly diagnosed malignancy in women. Studies suggest that around 232,340 new cases will be diagnosed and around 39,620 women will die due to breast cancer by the end of 2013 [1]. The HER2/neu is a proto-oncogene, which is amplified in several neoplasms like breast, salivary gland, stomach, kidney and lung [2-7]. It is overexpressed in about $30 \%$ of breast cancer patients, which leads to poor clinical outcomes [2-7]. HER2 is a mitogenic tyrosine kinase receptor, known to induce transforming signals and hence directly promotes cell proliferation [8]. The HER2 expression can lead to impaired DNA repair [8], angiogenesis [9] and metastasis [10]. Furthermore, HER2 has been shown to interact with several other growth promoting mechanisms like TGF $\beta$, estrogen receptor, FOXO1A, Src kinases, ILK and integrins to reinforce oncogenesis and metastasis [11-16]. Trastuzumab (herceptin) is a specific antibody for HER2 that is used against HER2+ breast cancer. But studies indicate limitations of trastuzumab therapy due to cardio-toxicity and resistance in patients [17].

Integrins is a large family of cell adhesion receptors, which also perform other diverse functions like cell survival and motility. Various integrins have been implicated in tumor cell survival, proliferation and metastasis $[18,19]$. Importantly, two major integrin heterodimers ITGAVB3 $(\alpha \mathrm{V} \beta 3)$ and ITGA6B4 $(\alpha 6 \beta 4)$ have been found to play specific role in breast cancer 
progression and metastasis [20-26]. There is a strong evidence that cross-talk between HER2 and ITGA6B4 promotes tumor aggressiveness [16, 27-29]. ITGB4 (Integrin $\beta 4$ ) contributes to HER2 up-regulation in mammary tumors suggesting a strong correlation between HER2 and integrins in mammary tumor development and progression [30]. Identification of novel agents that can target both HER2 and integrin signaling could be beneficial for the treatment of breast cancer overexpressing HER2.

Cucurbitacins are triterpenoid steroidal compounds mainly present in the Cucurbitaceae family of plants [31]. Several evidences suggest the cytotoxic properties of Cucurbitacin $\mathrm{B}(\mathrm{CuB})$ through cell cycle arrest and STAT3 inhibition in pancreatic cancer and hepatocellular carcinoma [32-35]. However, the exact mechanism of $\mathrm{CuB}$ is not clear.

The objective of the current study was to evaluate whether $\mathrm{CuB}$ could suppress breast cancer growth by inhibiting HER2/integrin signaling. Our results showed that $\mathrm{CuB}$ inhibits HER2 expression in breast cancer cells through ILK1 and YB-1 in both in vitro and in vivo models. In addition, it was observed that $\mathrm{CuB}$ inhibits ITGA6B4 (integrin $\alpha 6 \beta 4$ ) signaling and the subsequent cross-talk with HER2. Our study provides a novel insight into the mechanism of action of $\mathrm{CuB}$ along with evidence for the role of HER2-integrin signaling in breast cancer.

\section{RESULTS}

\section{CuB inhibits breast cancer cell growth by inducing apoptosis}

Considering breast tumor heterogeneity, we used four different cell lines with diverse phenotype and genotype. Treatment of MDA-MB-231, SKBR3, MCF-7 and 4T-1 breast cancer cells with increasing concentrations of $\mathrm{CuB}$ significantly reduced the survival of these cells in a concentration and time-dependent manner with an IC50 ranging between $18-50 \mathrm{nM}$ after 48 and $72 \mathrm{~h}$ treatment (Fig. 1A - D). Previous studies reported significantly high IC50 of CuB in normal mammary epithelial cell lines as compared to SKBR3 breast cancer cells [36]. To confirm the non-toxic effects of $\mathrm{CuB}$, we evaluated its toxicity in a normal human melanocyte epithelial (PIG1) cells. Our results showed that the viability of PIG1 cells treated with $\mathrm{CuB}$ was least affected as compared to the viability of cancer cells (Suppl. Fig 1A). For example, treatment of with $50 \mathrm{nM} \mathrm{CuB}$ for $72 \mathrm{~h}$ inhibited the growth of PIG1 cells by $20-30 \%$ only. However, the growth of cancer cell lines like SKBR3, MDA-MB-231, MCF-7 and 4-T1 were inhibited by $50-70 \%$ after treatment with $\mathrm{CuB}$ under similar conditions (Suppl. Fig 1B). These results along with previous observations suggest that $\mathrm{CuB}$ is relatively non-toxic to the normal cells at the concentrations required for inhibiting the growth of cancer cells.

To explore the mechanism of the growth inhibitory effects of CuB, MDA-MB-231, SKBR3 and MCF-7 cells were treated with $0,15,25,50$ and $75 \mathrm{nM} \mathrm{CuB}$ for 48 or 72h. 4T-1 cells required higher concentration of $\mathrm{CuB}$ for induction of apoptosis and the molecular changes hence were treated with $0,20,40,80$ and $150 \mathrm{nM} \mathrm{CuB}$ for $48 \mathrm{~h}$. The cells were analyzed for apoptosis using Annexin V assay. As shown in Fig. 1E \& F, $75 \mathrm{nM} \mathrm{CuB}$ treatment for $72 \mathrm{~h}$ induced apoptosis in about $80 \%$ of SKBR3 cells and about $60 \%$ in MDA-MB-231, MCF-7 and 4T-1 cells. To further investigate the mechanism of apoptosis in $\mathrm{CuB}$ treated breast cancer cells, western blot analysis was performed. The western blot data of whole cell lysates from $\mathrm{CuB}$ treated MDA-MB-231, SKBR3, MCF-7 and 4T-1 cells showed significant down-regulation of $\mathrm{Bcl} 2$ and survivin (Fig. 2A-D). Although, SKBR3 cells expressed low constitutive levels of Bcl2 and survivin, the extent of apoptosis induced by $\mathrm{CuB}$ was comparable with other cell lines indicating the role of multiple pathways in $\mathrm{CuB}$ mediated cell death. On the other hand, expression of pro-apoptotic BIM was up-regulated along with cleavage of Caspase 8 (Fig. 2A-D). We were unable to detect the cleaved fragments of Caspase 3 and hence looked at full length Caspase 3 (pro-caspase 3). The expression of fulllength Caspase 3 decreased in response to $\mathrm{CuB}$ treatment in all the cell lines tested indicating apoptosis (Fig. 2A-D). These observations indicate the concentration-dependent induction of apoptosis by $\mathrm{CuB}$ in breast cancer cells.

Interestingly, we observed cleavage of BAX by $\mathrm{CuB}$ treatment. Expression of BAX generally increases in response to apoptotic stimuli leading to caspase activation [37]. BAX cleavage mediated by caspases or calpains is known to play a much stronger role in apoptosis $[38,39]$. We observed that $\mathrm{CuB}$ treatment caused a concentration dependent cleavage of BAX at both $48 \mathrm{~h}$ and $72 \mathrm{~h}$ time points in MDA-MB-231 and SKBR3, while no cleavage was observed in MCF-7 cells (Fig. 2A-C). To prove it further, MDA-MB-231 cells were treated with caspase 3 inhibitor along with $\mathrm{CuB}$ treatment. The results from this experiment showed that caspase 3 inhibitor significantly blocked $\mathrm{CuB}$ mediated cleavage of BAX (Fig. 2E). Since MCF-7 is a caspase 3 null cell line, no cleavage of BAX was observed. These results indicate a direct role of caspase 3 in BAX cleavage in our model [40].

\section{CuB treatment suppresses HER2 signaling}

To determine the mechanism of cell death induced by $\mathrm{CuB}$ treatment, cell lysates were analyzed by western blotting. Our results showed that treatment of MDAMB-231, SKBR3, MCF-7 and 4T-1 cells with CuB after 48 or $72 \mathrm{~h}$ of treatment significantly reduced HER2 and EGFR expression in a concentration-dependent manner (Fig. 3A-D). Although both HER2 and EGFR were 
A MDA-MB-231

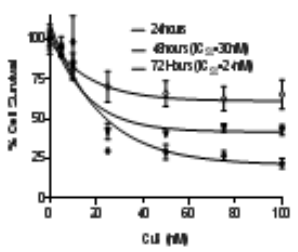

E
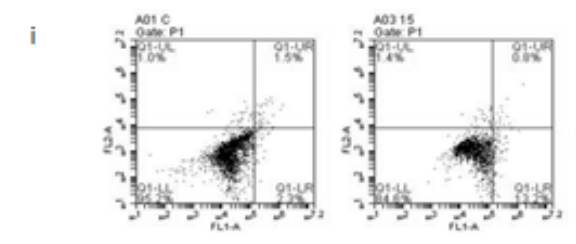

MDA-MB-231 (48h)
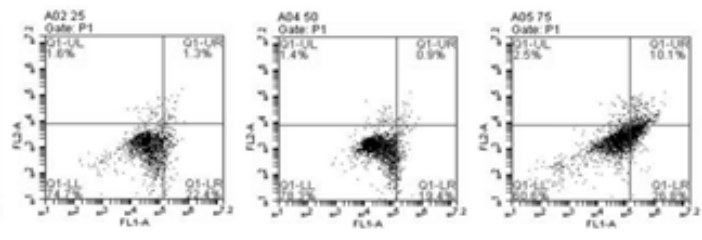

MDA-MB-231 (72h)

ii
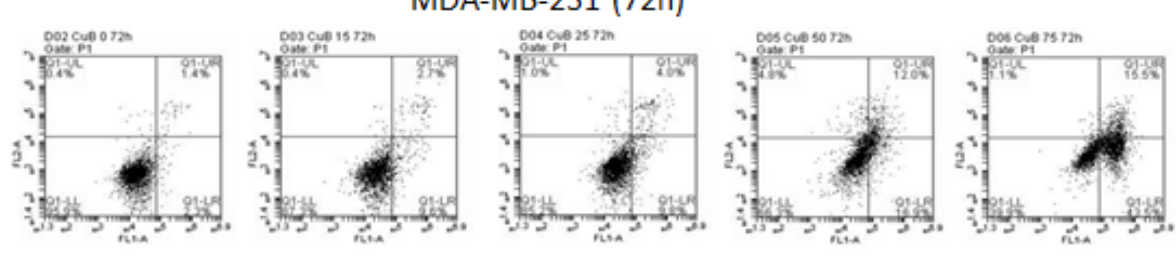

$\mathbf{F}$

MDA-MB-231
C $\quad$ MCF-7

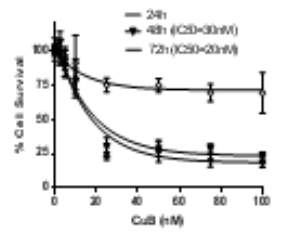

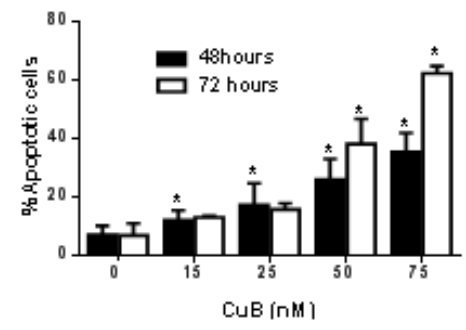

iii

MCF-7
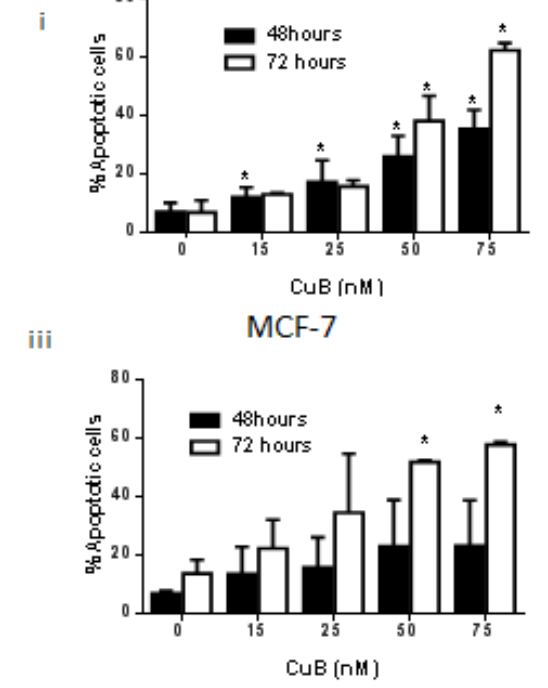

SKBR-3

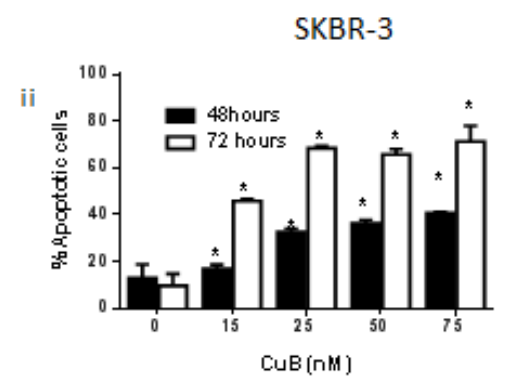

iv

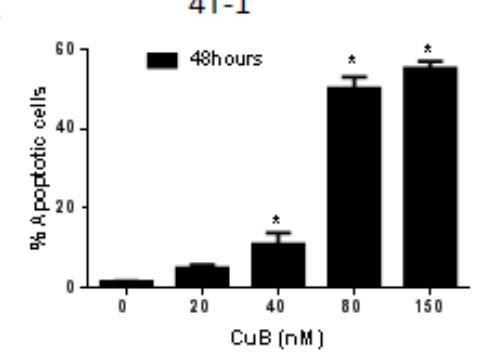

D $\quad 4 \mathrm{~T}-1$

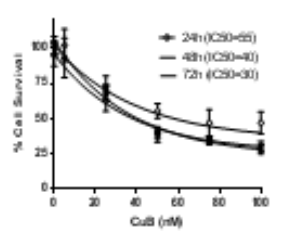

Figure 1: CuB induces cell death in breast cancer cells. (A) MDA-MB-231, (B) SKBR3 (C) MCF-7 \& (D) 4T-1 cells were treated with increasing concentrations of $\mathrm{CuB}$ for $48 \mathrm{~h}$ or 72 . Cell survival was measured with sulforhodamine $\mathrm{B}$ assay to estimate the $\mathrm{IC}_{50}$ values. The experiments were repeated at least three times with 8 replicates in each experiment. Apoptosis induction was measured in cells treated with various concentrations of $\mathrm{CuB}$ using Annexin V-FITC assay and Accuri C6 flowcytometer. (E) Representative figure of apoptosis in MDA-MB-231 cells treated with $\mathrm{CuB}$ (i) $48 \mathrm{~h}$ and (ii) $72 \mathrm{~h}$. (F) Concentration dependent apoptosis induction in various cell lines after 48 and 72h of CuB treatment (i) MDA-MB-231 (ii) SKBR3 (iii) MCF-7 and (iv) 4T-1 cells. Each experiment was repeated more than three times independently. *Statistically significant when compared to control $(\mathrm{p}<0.05)$ 
A

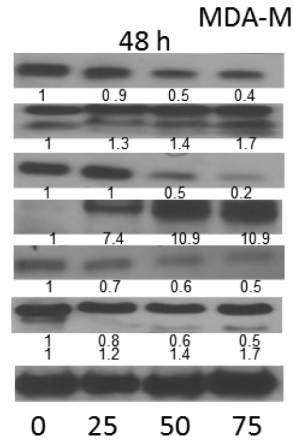

B

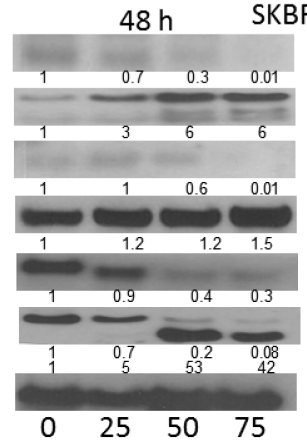

SKBR
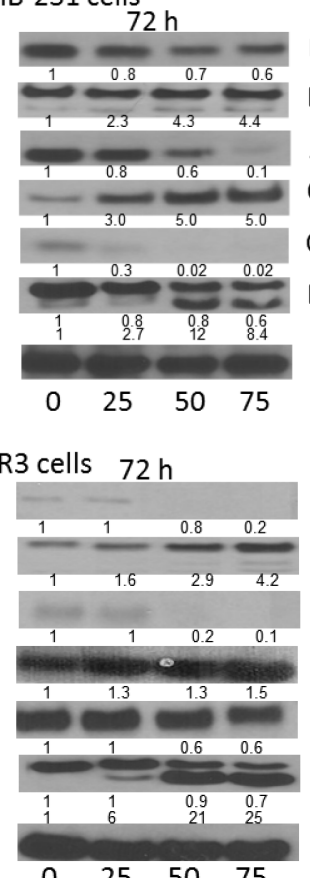

$\mathrm{Bcl} 2$

BIM

Survivin

Casp 8 (Cleaved)

Casp 3 (Full Length)

BAX

Histone H3

$\mathrm{CuB}(\mathrm{nM})$

$\mathrm{BCl} 2$

BIM

Survivin

Casp 8 (Cleaved)

Casp 3 (Full Length)

BAX

Histone $\mathrm{H} 3$

$\mathrm{CuB}(\mathrm{nM})$

C

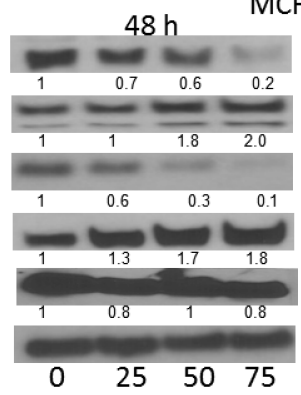

\section{cells $72 \mathrm{~h}$}

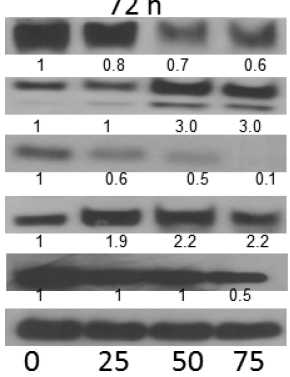

$\mathrm{Bcl} 2$

BIM

Survivin

Casp 8 (Cleaved)

BAX

Histone $\mathrm{H} 3$

CuB (nM)

D

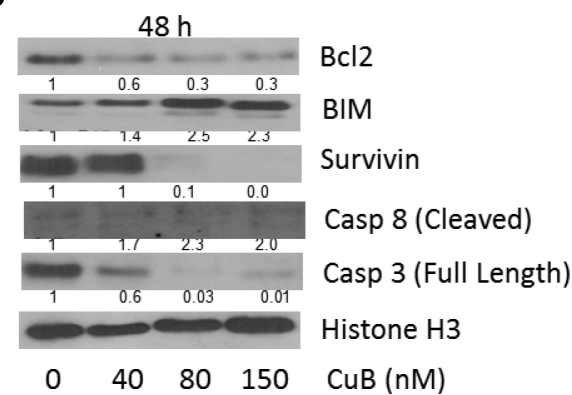

E

MDA-MB-231 cells

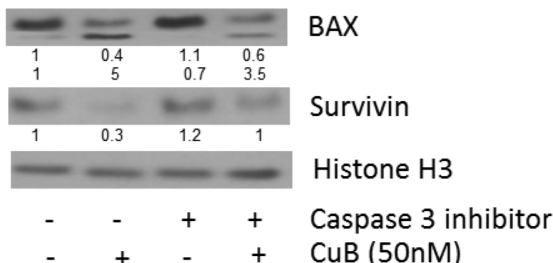

Figure 2: Induction of caspase mediated apoptosis by CuB: (A) MDA-MB-231 and (B) SKBR3 (C) MCF-7 and (D) 4T-1 cells were treated with varying concentrations of $\mathrm{CuB}$ for 48 or $72 \mathrm{~h}$. Representative blots showing the concentration dependent effect of $\mathrm{CuB}$ on Bcl2, BIM, Survivin, Caspase 8 (cleaved) and Caspase 3 (full length). (E) MDA-MB-231 cells were treated with Q-VD-OPH, a specific inhibitor for caspase $3,1 \mathrm{~h}$ prior to $\mathrm{CuB}$ treatment. The cells were collected after $48 \mathrm{~h}$ treatment and cell lysates were analyzed for BAX cleavage using western blot technique. Histone $\mathrm{H} 3$ was used as a loading control. Each experiment was repeated at least three times independently. 
reduced after $72 \mathrm{~h}$ of $\mathrm{CuB}$ treatment, effect of $\mathrm{CuB}$ was more pronounced at $48 \mathrm{~h}$ in SKBR3 and MCF-7 cells. $\mathrm{CuB}$ inhibited HER2 in all the cell lines irrespective of ER or p53 status. Phosphorylated EGFR was undetectable in MDA-MB-231, MCF-7 and 4T-1 cells. However, CuB treatment significantly suppressed the phosphorylation of EGFR at Y-992 after 72h treatment in SKBR3 cells (Fig. 3B). CuB treatment also substantially reduced the expression and phosphorylation of Src at Y-416 along with decreased phosphorylation of p130CAS at Y-410. The inhibitory effects of $\mathrm{CuB}$ on the phosphorylation and expression of Src varied with duration of treatment in MDA-MB-231, SKBR3 and MCF-7 cells (Fig. 3AD). However, longer treatment did not cause any further suppression of phosphorylated p130CAS in any cell line. p130CAS is a downstream effector molecule of Src. Src plays a vital role in the cross-talk of HER2 with integrins in breast tumors [16]. Furthermore, we observed suppression of TNF $\alpha$-converting enzyme protease (TACE) by $\mathrm{CuB}$ treatment (Fig. 3A-D). The $72 \mathrm{~h}$ treatment with $\mathrm{CuB}$ caused more TACE inhibition as compared to $48 \mathrm{~h}$ treatment in MDA-MB-231 and MCF-7 cells (Fig. 3A \& C). TACE has been implicated in the activation of EGFR and HER 2 by TGF $\beta[16,41]$. Since $\mathrm{CuB}$ down-regulated HER2 expression, it was important to test the effect of $\mathrm{CuB}$ on the regulatory molecules of HER2. As shown in Fig. 3A-D, treatment of cells with CuB substantially reduced the expression of ILK1 and Twist. It was observed that
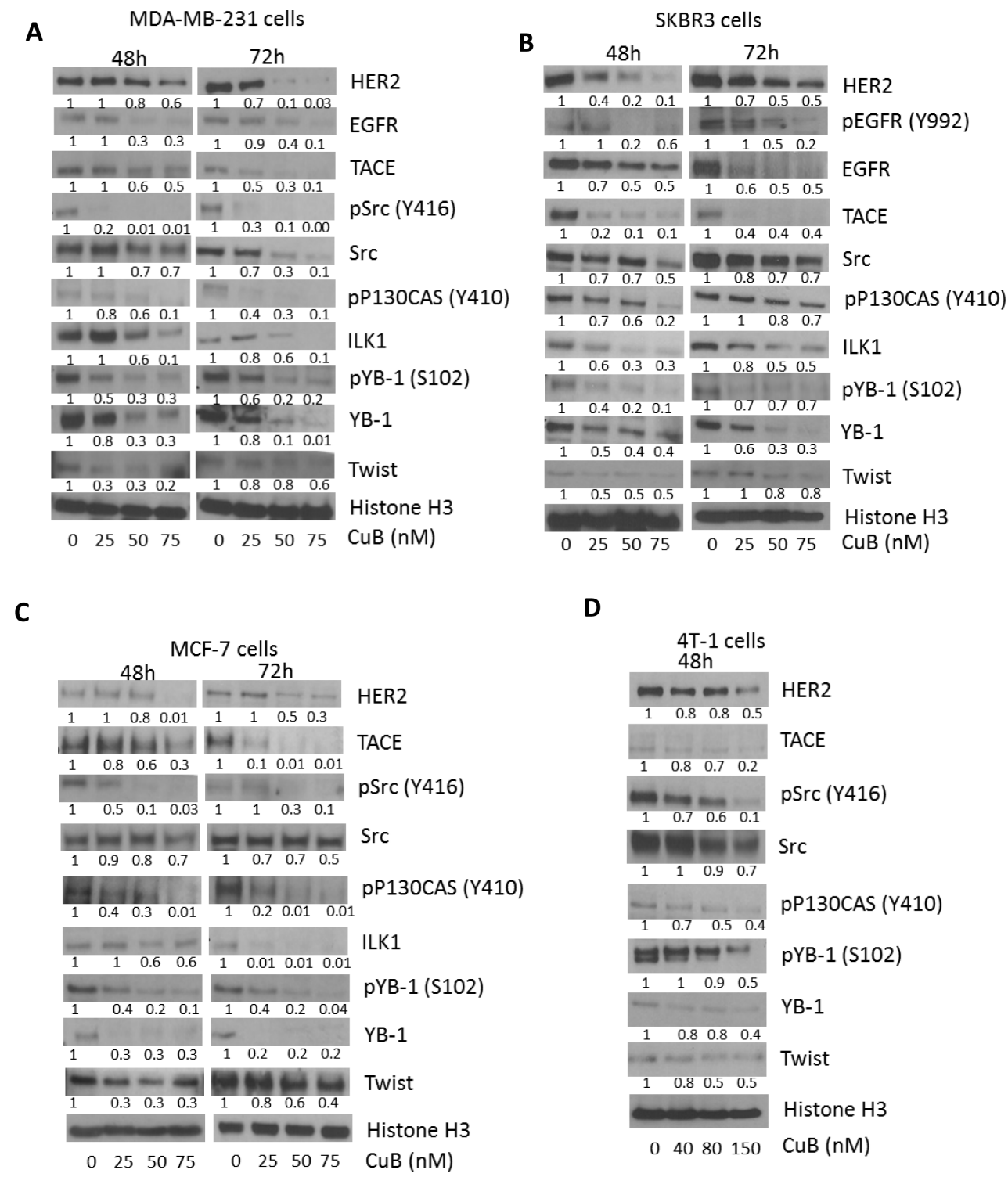

D

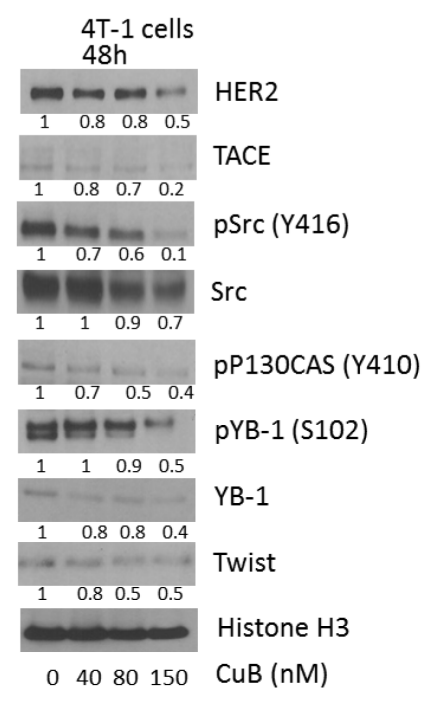

Figure 3: Suppression of HER2 and associated signaling by CuB treatment: (A) MDA-MB-231 (B) SKBR3 (C) MCF-7 and (D) 4T-1 cells were treated with varying concentrations of $\mathrm{CuB}$ for 48 or $\mathbf{7 2} \mathrm{h}$. Representative blots showing concentration dependent effect of CuB on HER2, EGFR, phospho EGFR (Y992) TACE, phosho-Src (Y416), Src, phospho-P130CAS (Y410), ILK1, phosphor-YB1 (S102), YB-1 and Twist. Histone H3 was used as a loading control. Each experiment was repeated atleast three times independently. 
in MCF-7 cells, CuB treatment reduced ILK1 expression more at $72 \mathrm{~h}$ treatment as compared to $48 \mathrm{~h}$. TWIST suppression was more pronounced at $48 \mathrm{~h}$ treatment with $\mathrm{CuB}$ in all the three cell lines. Furthermore, suppression of YB-1 expression as well its phosphorylation at S-102 was also observed with $\mathrm{CuB}$ treatment (Fig. 3A-D). The ILK1/ YB-1/Twist signaling axis has been known to regulate HER2 expression in breast cancer cells [15]. Our results showed that higher HER2 inhibition was observed at 48h in only those cell lines where TWIST along with ILK or YB1 were also inhibited. These observations suggest that inhibition of HER2 by $\mathrm{CuB}$ was associated with the inhibition of ILK1/YB-1 signaling.

A

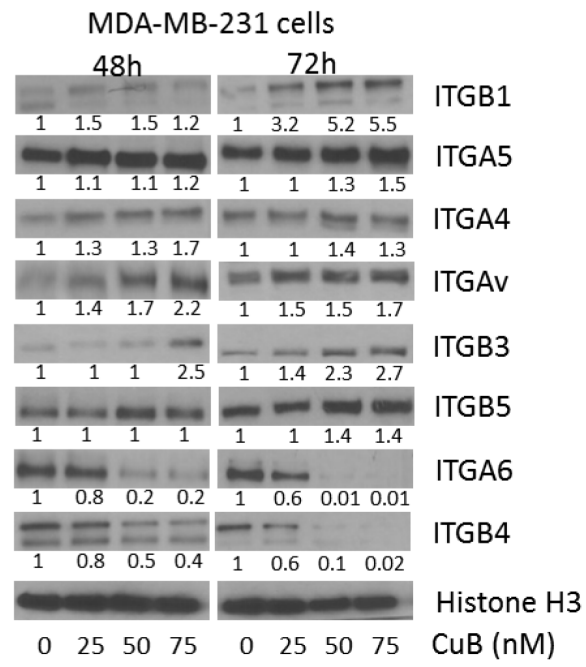

C

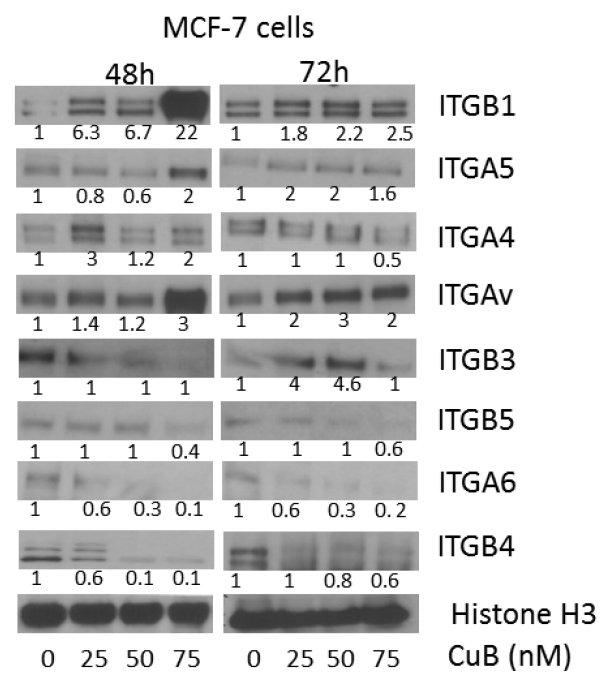

\section{CuB suppresses ITGA6B4}

To evaluate the role of $\mathrm{CuB}$ on integrin signaling, MDA-MB-231, SKBR3, MCF-7 and 4T-1 cells were treated with $\mathrm{CuB}$ for 48 and $72 \mathrm{~h}$. Our results showed that $\mathrm{CuB}$ significantly suppressed the expression of ITGA6 and ITGB4 as compared to other integrins in the cell lines tested in a time-dependent manner (Fig. 4A-D). The other integrins were either not affected at all or very modest changes were observed by $\mathrm{CuB}$ treatment. These results indicate that $\mathrm{CuB}$ causes specific inhibition of ITGA6 and ITGB4, which interestingly are overexpressed in breast cancer and interacts with HER2. On the other hand,

B

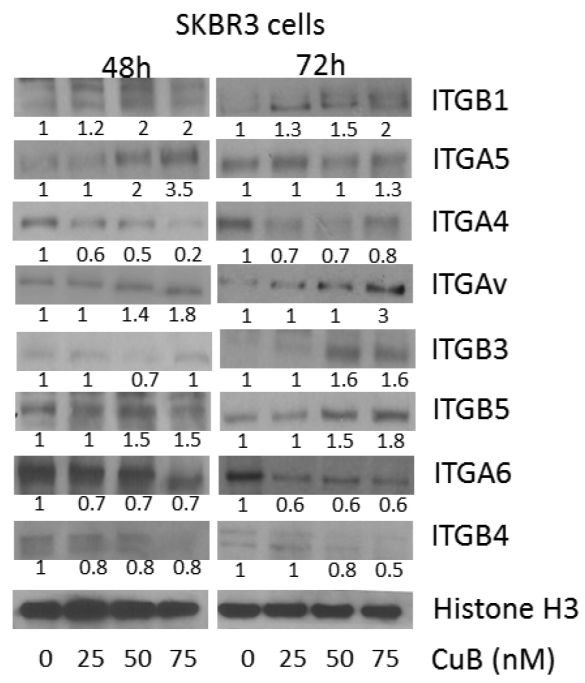

D

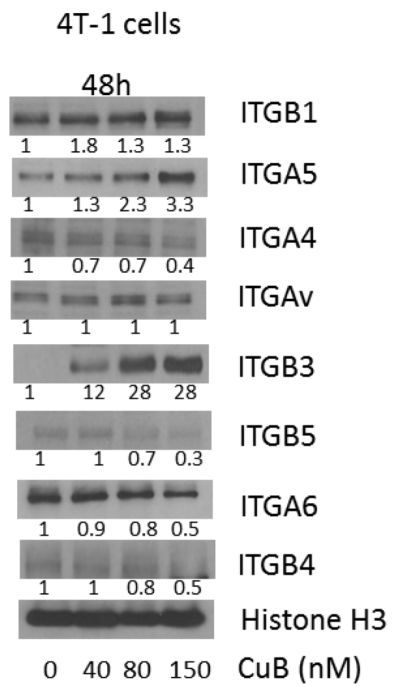

Figure 4: CuB suppresses integrin a6/ק4 expression: (A) MDA-MB-231 (B) SKBR3 (C) MCF-7 and (D) 4T-1 cells were treated with different concentrations of $\mathbf{C u B}$ for 48 or $\mathbf{7 2} \mathbf{h}$. The proteins in cell lysates were separated using western blot. The blots were immune-probed for the integrins ITGB1 (integrin $\beta 1$ ), ITGA5 (integrin $\alpha 5$ ), ITGAV (integrin $\alpha$ ), ITGB3 (integrin $\beta 3$ ), ITGB5 (integrin $\beta 5$ ), ITGA6 (integrin $\alpha 6$ ), ITGB4 (integrin $\beta 4$ ) and Histone H3 was used as the loading control. Each experiment was repeated atleast three times independently. 
the pro-apoptotic ITGB1 and ITGB3 were induced in a time-dependent manner in MDA-MB-231 and SKBR3 cells after treatment with similar concentrations of $\mathrm{CuB}$. Although, significant induction of ITGB1 was observed at $48 \mathrm{~h}$ treatment with $\mathrm{CuB}$ in $\mathrm{MCF}-7$ cells, cleavage of caspase 8 or apoptosis did not correlated as compared with other cells. The induction of pro-apoptotic ITGB1 and ITGB3 by $\mathrm{CuB}$ treatment suggests activation of integrins mediated cell death by $\mathrm{CuB}$ in MDA-MB-231, SKBR3 and 4T-1 breast cancer cells.

\section{CuB inhibits TGF $\beta$ mediated interaction of HER2 with ITGA6}

Since TGF $\beta$ is known to activate HER2/integrin signaling, we evaluated the interaction of HER2 with integrins. TGF $\beta$ treatment significantly increased the expression of ITGA6 by about 1.5 fold in MDA-MB-231 and 4T-1 cells (Fig. 5A). Interestingly, when HER2 was immune-precipitated from TGF $\beta$ treated cells, we observed that TGF $\beta$ treatment increased the expression of ITGA6 associated with HER2 (Fig. 5B). However, this interaction was inhibited by $\mathrm{CuB}$ treatment (Fig. 5C). These observations propose a novel mechanism of tumor promotion by TGF $\beta$ by increasing the association between ITGA6 and HER2, possibly due to induction of ITGA6. Our results thus provide a novel insight into TGF $\beta$ mediated physical interaction between HER2 and ITGA6. However, further studies are required to confirm the detailed mechanism and implications of this interaction.

To determine the effect of $\mathrm{CuB}$ on integrin signaling in presence of TGF $\beta$, MDA-MB-231 cells were treated with $\mathrm{CuB}(50 \mathrm{nM})$ after treatment with TGF $\beta(10 \mathrm{ng} / \mathrm{ml})$.

A

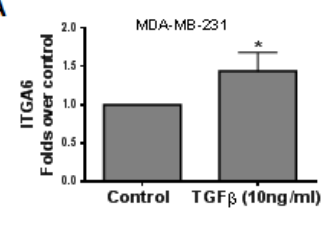

ITGA6

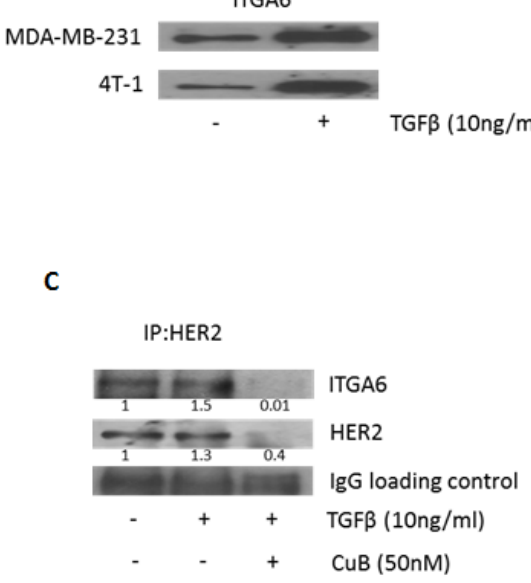

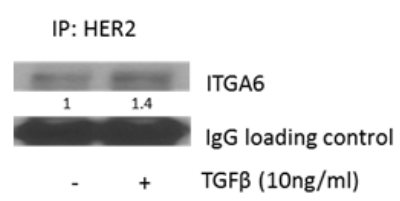

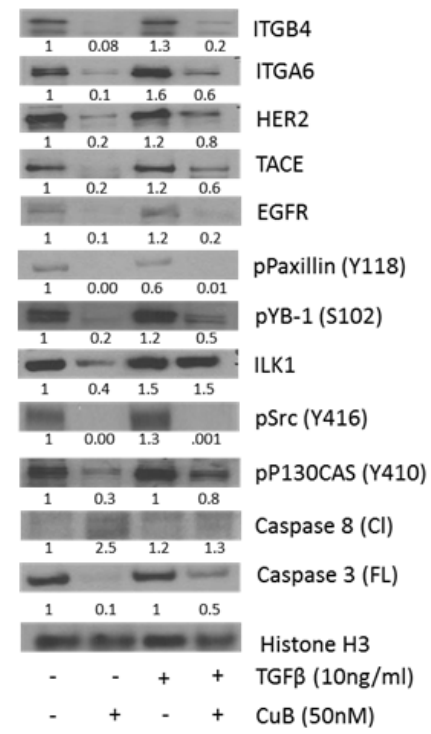

Figure 5: CuB inhibits TGF $\beta$-mediated interaction of HER2 and integrin $\alpha 6$ : (A) TGF $\beta$ treatment induces expression of integrin $\alpha 6$ in MDA-MB-231 and 4T-1 cells. (B) HER2 was immune-precipitated from MDA-MB-231 cell lysate with or without TGF $\beta$ treatment after $48 \mathrm{~h}$ and the protein was separated using western blot. The blots were probed for ITGA6. IgG was used as the loading control. (C) HER2 was immune-precipitated from cell lysates of MDA-MB-231 cells with or without treatment with TGF $\beta$ and CuB for 48h. The protein was separated using western blotting and the blots were probed for ITGA6 and HER2. IgG was used as the loading control (D) MDA-MB-231 cells were treated alone or in combination with TGF $\beta$ and $\mathrm{CuB}$ for $48 \mathrm{~h}$. The proteins in cell lysates were separated using western blot. The blots were probed for ITGB4, ITGA6, HER2, TACE, EGFR, phospho paxillin (Y118), phospho YB1 (S102), ILK1, phospho Src (Y416), phospho P130CAS (Y410), Caspase 8 (cleaved) and Caspase 3 (full-length). Histone H3 was used as a loading control. Each experiment was repeated atleast three times independently. 
Our results indicate that TGF $\beta$ significantly blocked $\mathrm{CuB}$ mediated inhibition of ITGA6, HER2, TACE, ILK1 and phosphoP130CAS (Y410) (Fig. 5D).

\section{Inhibition of integrin signaling by $\mathrm{CuB}$}

Next we tested the effects of $\mathrm{CuB}$ on downstream signaling of integrins in breast cancer cells. MDAMB-231, SKBR3, MCF-7 and 4T-1 cells were treated with various concentrations of $\mathrm{CuB}$ for 48 or $72 \mathrm{~h}$. As shown in Fig. 6A-D, CuB treatment suppressed the expression and phosphorylation of paxillin at Y-118 (Fig. 6A-D). A significant down-regulation of ILK1 was also observed by $\mathrm{CuB}$ treatment. ILK1-paxillin complex regulated by integrins serves as a major mechanism for various cell survival processes. $\mathrm{CuB}$ also inhibited the phosphorylation

of AKT at S-473 and ERK at T-202/204 (Fig. 6A-D). Both AKT and ERK are important downstream targets of ILK1paxillin complex. Consistently, $\mathrm{CuB}$ treatment suppressed the phosphorylation of GSK3 $\beta$ at S-9 while enhancing its protein level in a concentration and time dependent manner (Fig. 6A-D). AKT is known to negatively regulate GSK3 $\beta$ in cancer cells. CuB also suppressed ROCK1 and RhoA kinases which play important role in cell motility (Fig. 6A-D). Both the kinases are known to be activated by integrins and are important targets of Akt.

\section{CuB inhibits breast tumor growth in mice}

To test the efficacy of $\mathrm{CuB}$ in vivo, two breast tumor experiments were performed. In the first experiment, $5 \times 10^{6}$ MDA-MB-231 cells were injected orthotopically

A

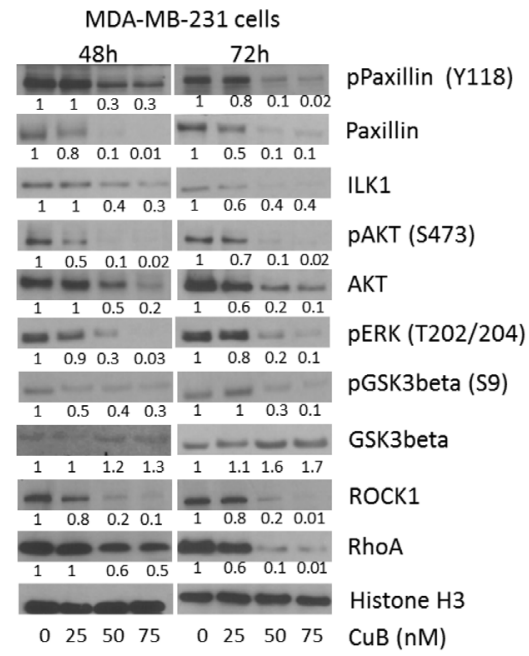

C

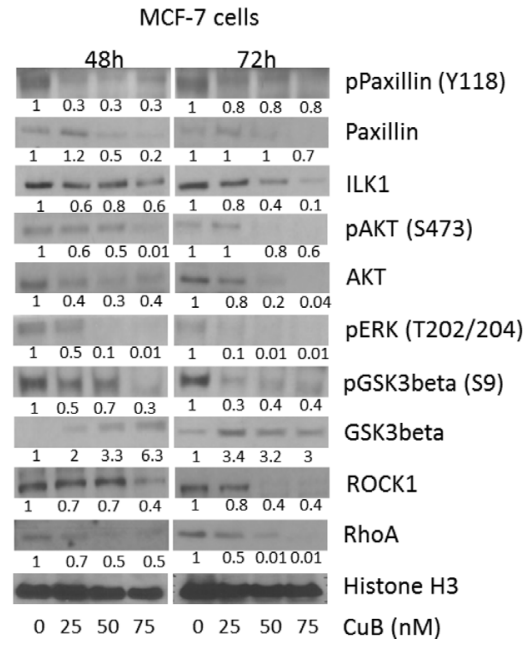

B

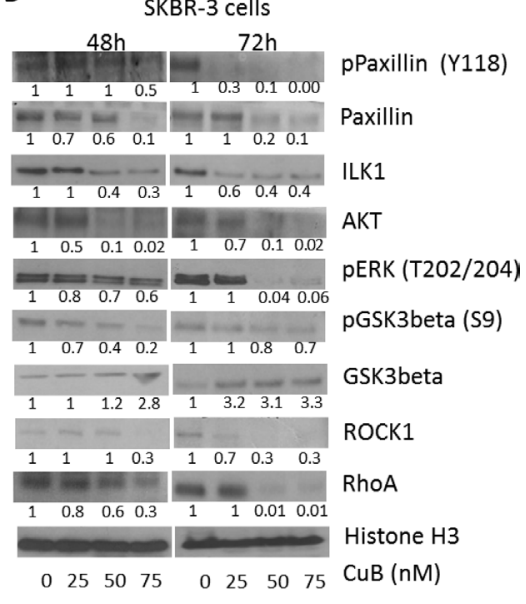

D

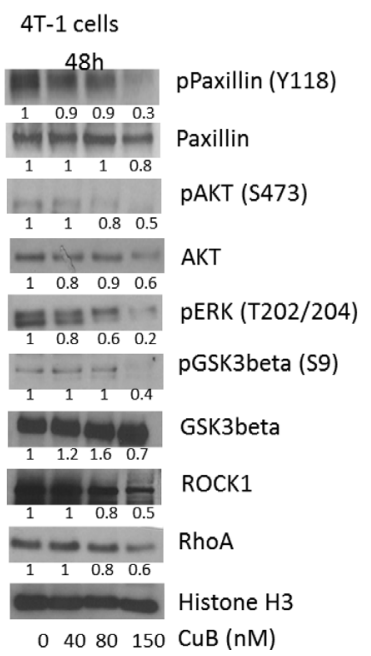

Figure 6: CuB inhibits integrin signaling cascade: (A) MDA-MB-231 (B) SKBR3 (C) MCF-7 and (D) 4 T-1 cells were treated with various concentrations of $\mathrm{CuB}$ for 48 or $72 \mathrm{~h}$. The cell proteins were separated using western blot. The blots were immune-probed for phospho paxillin (Y118), paxillin, ILK1, phospho Akt (S473), Akt, phospho ERK (T202/204), phospho GSK3 $\beta$ (S9), GSK3 $\beta$, ROCK1 and RhoA. Histone H3 was used as the loading control. Each experiment was repeated at least three times independently. 
in the mammary fat pads of female athymic nude mice. Once each mouse attained palpable tumors, mice were randomly divided into two groups with ten mice in each group. Treatment group received $2 \mathrm{mg} / \mathrm{kg} \mathrm{CuB}$ everyday by oral gavage. The tumor growth was monitored by measuring tumor volumes periodically. Our results showed that oral gavage of $\mathrm{CuB}$ significantly reduced the growth of breast tumors (Fig. 7A). At day 60 of the treatment, tumor volume in the treated group was reduced by $55 \%$ as compared to the control group $\left[249.5 \pm 30.3 \mathrm{~mm}^{3}\right.$ vs $\left.111.3 \pm 18.4 \mathrm{~mm}^{3} ;(\mathrm{n}=10)\right]$ (Fig. 7Ai). The weight of the MDA-MB-231 tumors dissected from treated mice was about $53 \%$ less than the weight of tumors from control mice (Fig. 7Aii). The weight of mice did not change significantly with oral gavage, indicating no apparent systemic toxicity in $\mathrm{CuB}$-treated mice (Fig. 7Aiii). In the other experiment, $0.1 \mathrm{X} 10^{6} 4 \mathrm{~T}-1$ breast cancer cells were injected in the mammary fat pads of female BALB/c mice. 4T-1 cells are highly aggressive and considered to be late stage breast cancer. Once each mouse attained palpable tumors, mice were segregated into two groups with eight mice in each group. $1 \mathrm{mg} / \mathrm{kg} \mathrm{CuB}$ was given intraperitoneally, every third day to the mice of treatment group and the growth of the tumors monitored. The growth of tumors in $\mathrm{CuB}$ treated group was reduced significantly as compared to control group (Fig. 7B). For example, at day 28 of the treatment, 4T-1 tumor volume in the treated group was reduced by $39 \%$ as compared to control group [2355.3 $\pm 236.4 \mathrm{~mm}^{3}$ vs $\left.1446.7 \pm 142.6 \mathrm{~mm}^{3} ;(\mathrm{n}=8)\right]$ (Fig. 7Bi). Similarly, the weight of the tumors in treated mice was reduced by $27 \%$ (Fig. 7 Bii \& iv). A transitory reduction in weight was observed in the mice receiving i.p. administration of $\mathrm{CuB}$ as compared to control, which ameliorated with time (Fig. 7Biii). Since the weight of the

A

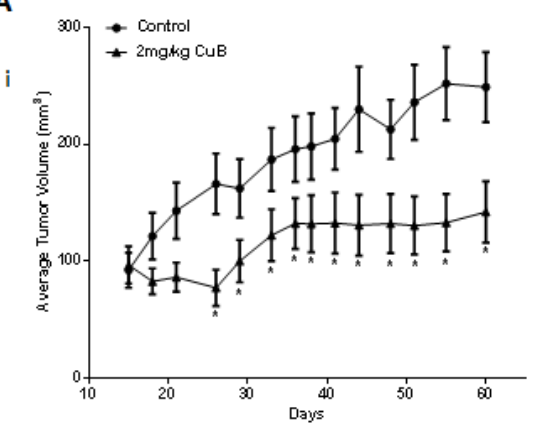

ii

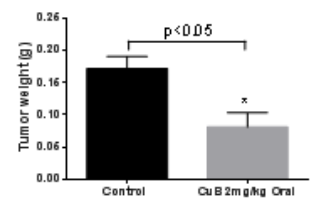

iii

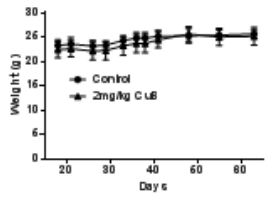

ii

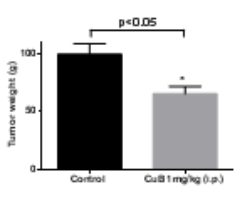

iii

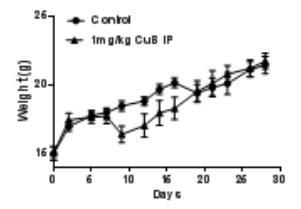

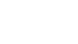

$\mathrm{CuB}(1 \mathrm{mg} / \mathrm{kg})$ i.p.
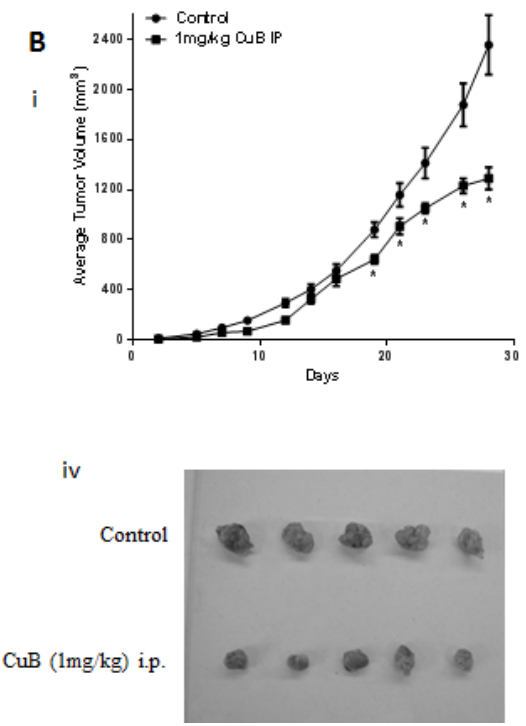

Figure 7: CuB suppresses breast tumor growth: (A) About 5X106 MDA-MB-231 cells were orthotopically implanted in the mammary fat pad of female athymic nude mice. Once each mouse had a tumor of about $50-80 \mathrm{~mm}^{3}, 2 \mathrm{mg} / \mathrm{kg} \mathrm{CuB}$ was administered by oral gavage every day. Tumors were measured periodically and each mouse was weighed every week. Effect of CuB on (i) tumor volume, (ii) tumor weight and (iii) mice weight. (B) About $0.1 \mathrm{X} 10^{6} 4 \mathrm{~T}-1$ cells were orthotopically implanted in the mammary fat pad of female BALB/c mice. Once each mouse had a tumor of about $30-50 \mathrm{~mm}^{3}, 1 \mathrm{mg} / \mathrm{kg} \mathrm{CuB}$ was injected by i.p route every third day. Tumors were measured periodically and each mouse was weighed every week. Effect of $\mathrm{CuB}$ on (i) tumor volume, (ii) tumor weight (iii) mice weights and (iv) representative tumor size after dissection. 
Table 1: Body weight and organ weight data from control and $\mathrm{CuB}$ treated mice

\begin{tabular}{|l|l|l|l|l|l|l|l|l|l|}
\hline Treatment & $\begin{array}{l}\text { body weight } \\
(\mathrm{g})\end{array}$ & Liver $(\mathrm{g})$ & Liver/BW & Spleen $(\mathrm{g})$ & Spleen/Bw & Kidney $(\mathrm{g})$ & $\begin{array}{l}\text { Kidney/ } \\
\text { Bwa }\end{array}$ & Lungs $(\mathrm{g})$ & Lungs/Bw $^{\mathrm{a}}$ \\
\hline Control & $20.79 \pm 0.86$ & $1.60 \pm 0.11$ & $0.076 \pm 0.00$ & $0.94 \pm 0.11$ & $0.04 \pm 0.00$ & $0.41 \pm 0.02$ & $0.02 \pm 0.00$ & $0.30 \pm 0.02$ & $0.01 \pm 0.00$ \\
\hline $\begin{array}{l}\text { CuB } 1 \mathrm{mg} / \\
\text { kg i.p. }\end{array}$ & $19.15 \pm 1.17$ & $1.53 \pm 0.10$ & $0.08 \pm 0.00$ & $0.7 \pm 0.10$ & $0.04 \pm 0.00$ & $0.43 \pm 0.02$ & $0.02 \pm 0.01$ & $0.33 \pm 0.02$ & $0.02 \pm 0.00$ \\
\hline
\end{tabular}

\begin{tabular}{|l|l|l|l|l|}
\hline Treatment & Brain $(\mathrm{g})$ & Brain $/ \mathrm{Bw}^{\mathrm{a}}$ & Heart $(\mathrm{g})$ & Heart $/ \mathrm{Bw}^{\mathrm{a}}$ \\
\hline Control & $0.41 \pm 0.01$ & $0.02 \pm 0.00$ & $0.15 \pm 0.01$ & $0.01 \pm 0.00$ \\
\hline CuB 1mg/kg i.p. & $0.38 \pm 0.03$ & $0.02 \pm 0.01$ & $0.17 \pm 0.02$ & $0.01 \pm 0.01$ \\
\hline
\end{tabular}

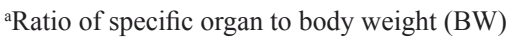

mice dropped initially after intraperitoneal administration, we decided to evaluate the mice of treated group for any signs of gross toxicity. The organs of control and treated mice were weighed once the experiment was terminated. No change in the weight of organs like liver, spleen, kidney, lungs, brain and heart were observed in $\mathrm{CuB}$ treated mice as compared to control mice (Table 1). The enzymatic activities of AST, ALT and LDH were also evaluated in the plasma of control and $\mathrm{CuB}$ treated mice. Although, no significant change in the activity of ALT and AST was observed, interestingly, plasma LDH level was reduced by $24.3 \%$ in the mice of $\mathrm{CuB}$ treated group (Table 2 ). The exact reasons behind the decrease in LDH level by $\mathrm{CuB}$ treatment was not clear and require further studies.

To determine if the tumor growth suppression in vivo by $\mathrm{CuB}$ was associated with the inhibition of HER2/integrins, immunohistochemistry (IHC) of tumor sections and western blot of the tumor tissue lysates was performed. The tumor sections from $\mathrm{CuB}$ treated mice showed reduced expression of HER2 and ITGB4 in MDA-MB-231 as well as 4T-1 tumor sections (Fig. 8 A \& B). Our western blot results also confirmed that the expression of HER2, ITGA6 and ITGB4 were suppressed in the tumors of $\mathrm{CuB}$ treated mice (Fig. 8A \& B). Tumor lysates from $\mathrm{CuB}$ treated mice also revealed suppression of phospho YB-1 (S-102) and Twist, which are known to regulate HER2 expression in breast cancer cells. In addition to suppression of HER2-associated signaling, $\mathrm{CuB}$ treatment also inhibited integrins' downstream signaling molecules like phospho paxillin (Y118) and ILK1 in the tumors. The induction of apoptosis by $\mathrm{CuB}$ treatment was confirmed through down-regulation of Bcl2 and pro-caspase 3 in the tumors of $\mathrm{CuB}$ treated mice. Taken together, these results indicate that the breast tumor growth suppression by $\mathrm{CuB}$ in vivo was associated with the inhibition of HER2/integrin signaling validating our in vitro observations.

\section{DISCUSSION}

HER2 overexpression is observed in about onefourth of breast cancer patients and is a major cause for poor prognosis [3]. The crosstalk of HER2 with several other growth signaling pathways results in extremely aggressive form of cancer, imparting high resistance to conventional therapeutic modalities [42]. Our study identified a unique HER2-integrin signaling axis in breast cancer that was inhibited by $\mathrm{CuB}$, a novel steroidal triterpenoid compound [31].

Several previous studies used $\mathrm{CuB}$ extracted from plants instead of using commercially available pure compound to evaluate cytotoxicity. Tannin-Spitz et. al. used the plant extract to evaluate the cytotoxic properties of $\mathrm{CuB}$ [43]. This study showed an IC50 of $8 \mu \mathrm{M}$ in MDA-MB-231 cells after $48 \mathrm{~h}$ of treatment. On the other hand, Promkan et al. observed an IC50 of $70 \mu \mathrm{M}(38.9 \mu \mathrm{g} /$ $\mathrm{ml}$ ) after $48 \mathrm{~h}$ of treatment [44]. In contrast to these studies, our study showed significantly reduced effective concentrations of $\mathrm{CuB}$. The IC50 of $\mathrm{CuB}$ after $72 \mathrm{~h}$ of treatment ranged between $18 \mathrm{nM}$ and $50 \mathrm{nM}$ in most of the breast cancer cell lines tested. Our results are in agreement with the IC50 observed by Wakimoto et. al., who used pure $\mathrm{CuB}$ [45]. Hence, differences in the IC50 of $\mathrm{CuB}$ in the published literature could be attributed to the purity of $\mathrm{CuB}$ and cancer model. We observed that $\mathrm{CuB}$ was effective in 4T-1 cells at slightly higher concentrations as compared to other cell lines. This could be due to several reasons: 4T-1 cells overexpress p-glycoprotein (P-gp) and hence is resistant to several chemotherapeutic agents [46]. It is possible that $\mathrm{CuB}$ could be the substrate for P-gp, leading to a requirement of higher concentrations of $\mathrm{CuB}$ in this cell line. Secondly, 4T-1 is a very aggressive and resistant cell line as compared to other cells used in our study, thus needing more $\mathrm{CuB}$ to suppress its growth.

Our studies showed that $\mathrm{CuB}$ treatment induced caspase mediated apoptosis in breast cancer cells. Apoptosis was confirmed through cleavage of caspase 8 and inhibition of full-length caspase 3. It is known that $\mathrm{Bcl} 2$ and survivin play a crucial role in caspase inhibition 
Table 2: The enzymatic activities of AST, ALT and LDH in the plasma of control and CuB treated mice

\begin{tabular}{|l|l|l|l|}
\hline & AST & ALT & LDH \\
\hline Control & $108.59 \pm 8.12$ & $13.51 \pm 1.6$ & $260.91 \pm 29.1$ \\
\hline CuB $1 \mathrm{mg} / \mathrm{kg}$ i.p. & $90.54 \pm 19.5$ & $18.41 \pm 1.6$ & $197.25 \pm 47.35$ \\
\hline
\end{tabular}
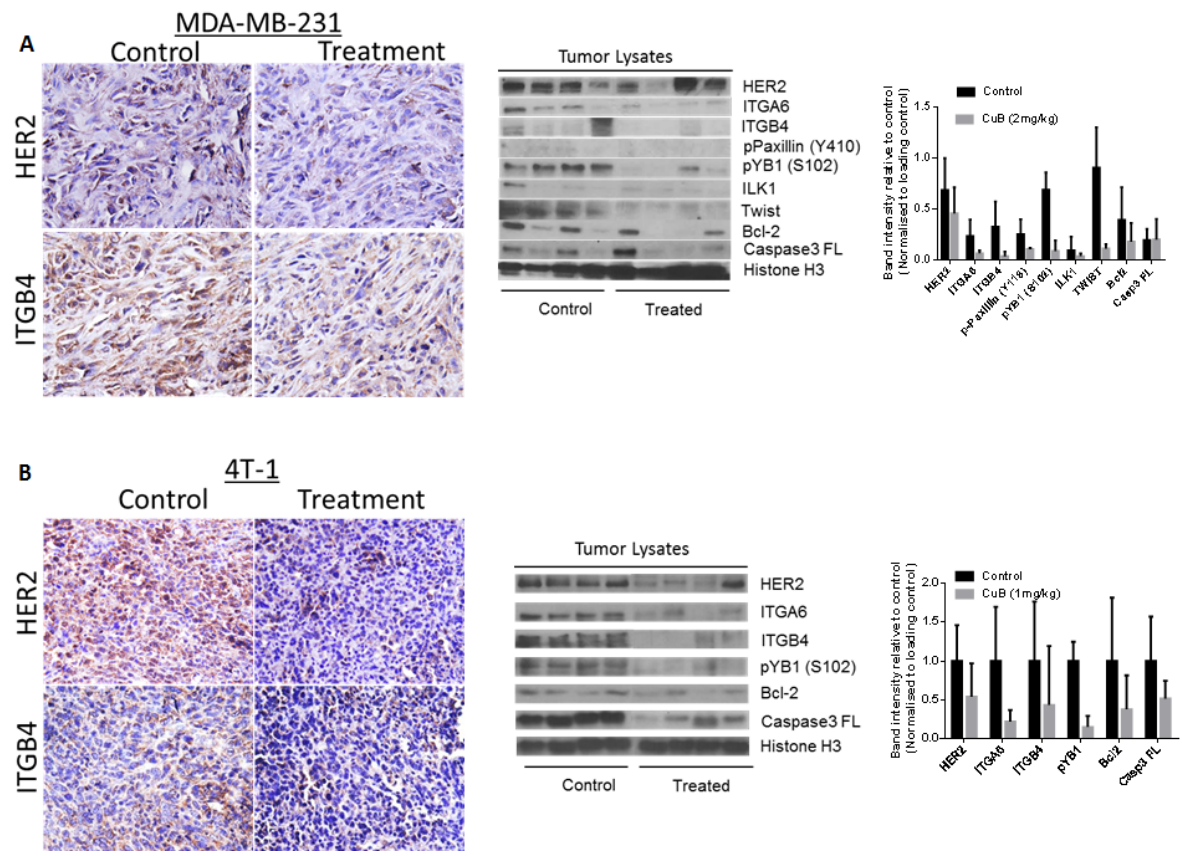

Figure 8: In vivo suppression of HER2-Integrin signaling by $\mathrm{CuB}$ treatment: Tumors were removed after the termination of the experiment. Tumors were minced, lysed and analyzed for HER2, ITGA6, ITGB4, phospho paxillin (Y118), phospho YB1 (S102), ILK, Twist, Bcl2 and Caspase 3. Blots were stripped and re-probed with Histone H3 antibody to verify equal protein loading. (A) Each lane of blot represents a tumor sample from individual mouse. The blots were quantitated, normalized with loading control and represented as bars. (B) Representative images from the control and CuB treated mice i) MDA-MB-231 tumors stained for HER2 and ITGB4 ii) 4T-1 tumors stained for HER2 and ITGB4

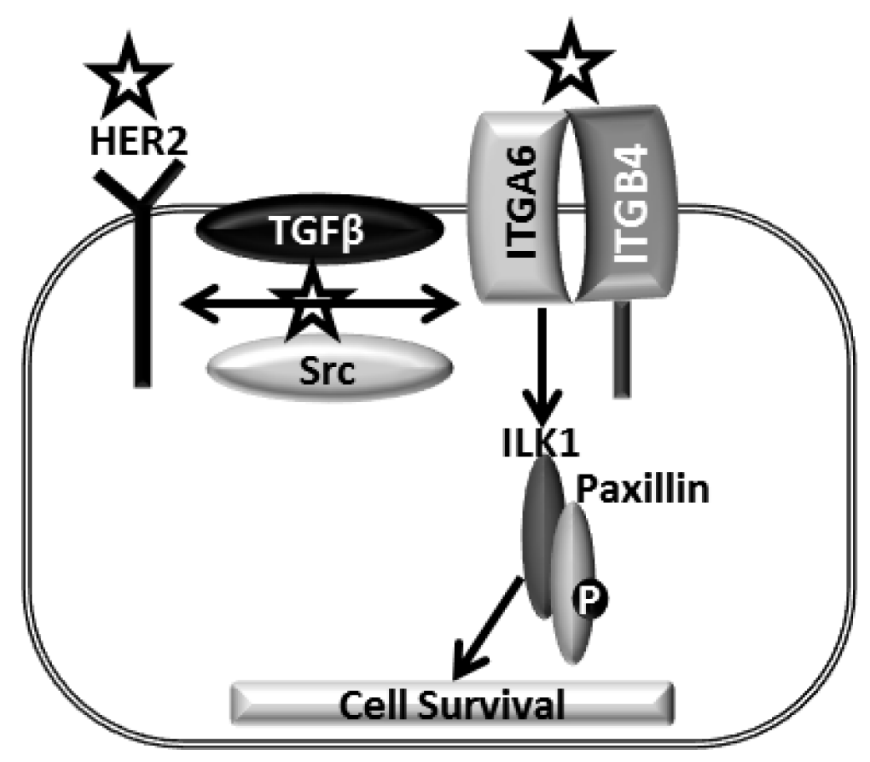

Figure 9: Model mechanism of $\mathrm{CuB}$ in breast cancer cells: HER2, an important oncogene enhances breast cancer progression. HER2-integrin cross-talk mediated by TGF $\beta$ or Src further promotes breast cancer. The complex of ILK1 and Paxillin orchestrates the downstream effects of integrins. Symbol represents the targets inhibited by $\mathrm{CuB}$. 
and their inhibition leads to activation of caspases. We observed significant reduction of these proteins by $\mathrm{CuB}$ treatment. Although, SKBR3 cells expressed low constitutive levels of $\mathrm{Bcl} 2$ and survivin, the apoptosis inducing effect of $\mathrm{CuB}$ was not compromised in SKBR3 cells, suggesting the role of other intermediary molecules. $\mathrm{BAX}$ is an important protein that regulates the activation of caspases and accumulation of BAX leads to apoptosis [37]. On the other hand, several studies have shown that cleavage of BAX mediated by caspases and calpains also plays a critical role in apoptosis $[38,39]$.Our results showed a concentration-dependent cleavage of BAX by $\mathrm{CuB}$ treatment in MDA-MB-231 and SKBR3 cells. However, the cleavage of BAX was not observed in MCF7 cells. This is not surprising as MCF-7 is a caspase 3 null cell line [40]. Cleavage of BAX by $\mathrm{CuB}$ was significantly blocked by caspase 3 inhibitor. These observations suggest a direct role of caspase 3 in BAX cleavage induced by $\mathrm{CuB}$ treatment. However, further studies are required to confirm the mechanism and implications of BAX cleavage by $\mathrm{CuB}$.

Our results indicated TGF $\beta$ mediated interaction of HER2 with integrins. HER2 utilizes multiple mechanisms to enhance tumorigenicity. Kalra et. al. have shown that ILK1 regulates HER2 expression by coordinating the molecular functions of TWIST and YB-1 [15]. In agreement, our results showed that $\mathrm{CuB}$ treatment inhibited ILK1/YB-1/TWIST signaling, which can explain the down-regulation of HER2 in our model.

Furthermore, the tumorigenicity by EGFR family of receptors is known to be mediated by Src kinase and Src inhibition can lead to suppression of tumorigenicity $[14,47]$. Our results demonstrated significant inhibition of Src expression and phosphorylation by $\mathrm{CuB}$ treatment. These changes were accompanied with suppression of phosphorylated P130CAS, the downstream effector molecule of Src kinase [48]. Interestingly, TACE dependent ligand shedding is also known to play role in regulating HER2-integrin signaling in breast cancer [16]. We observed suppression of TACE expression by $\mathrm{CuB}$ treatment in all the breast cancer cell lines tested. These observations suggest significant influence of $\mathrm{CuB}$ treatment on HER2 and related signaling in breast cancer irrespective of genotypes and phenotypes of various breast cancer cells used in our studies.

Integrins are the master regulators of various cellular processes [49]. ITGA6B4 has been recently identified to play a significant role in breast cancer progression through diverse mechanisms [20, 21, 26, 50-53]. ITGB4 is of special prognostic significance in basal type breast cancer exemplified by MDA-MB-231 cells used in this study [54]. Evidence suggests that HER2 is present at the crossroad of integrin signaling in breast cancer [27, 29, 55]. Guo et. al. demonstrated that ITGB4 augments HER2 signaling to promote breast cancer progression, while another study by Wang et. al. demonstrated augmentation of ITGA6B4 by HER2 [28, 30]. Furthermore, a study supports the physical interaction of HER2 with ITGA6, ITGB1 and ITGB4, which can be augmented by TGF $\beta$ [16]. These studies also suggest that inhibition of the interaction of HER2 with integrins can be exploited for therapeutic advantage [16]. Our studies confirm the interaction of HER2 with ITGA6. Interestingly, we made a unique observation that TGF $\beta$ treatment also increased the constitutive expression of ITGA6, which might be the reason of enhanced interaction of ITGA6 with HER2 by TGF $\beta$ treatment. Nonetheless, this interaction was inhibited by $\mathrm{CuB}$ treatment. Our observations confirm the interplay between HER 2 and integrin $\alpha 6 \beta 4$ in breast cancer cells, while suggesting a direct role of TGF $\beta$ in enhancing the interaction. Our results also suggest that inhibition of HER2 interaction with these integrins can serve as a powerful mechanism for anti-cancer therapeutics.

In addition to cross-talk with HER2, integrin heterodimers also enhance cell survival by direct signaling [56]. The cytoplasmic domains of heterodimers of $\beta$ integrins can interact with adaptor proteins like ILK (Integrin linked Kinase) and paxillin to enhance survival signals through AKT and ERK, leading to inactivation of GSK $3 \beta$ and activation of Rho kinases like ROCK1 and RhoA [57, 58]. Our data clearly shows inhibition of ILK1, paxillin, Akt, ERK and Rho kinases while inducing GSK3 $\beta$ by CuB treatment in breast cancer cells. Our timedependent study indicated that HER2 inhibition was more prominent at $48 \mathrm{~h}$ of $\mathrm{CuB}$ treatment whereas, inhibition of integrins was more at $72 \mathrm{~h}$. Therefore, these results suggest that inhibition of integrin followed HER2 inhibition, indicating a link between these pathways.

Interestingly, ITGB1 and ITGB3 have been shown to induce apoptosis through recruitment of caspase8, the process known as integrin-mediated death (IMD) [18]. We observed an increase in the expression of ITGB1, ITGB 3 and cleavage of caspase 8 by $\mathrm{CuB}$ treatment in MDA-MB-231, SKBR3 and 4T-1 cells, suggesting CuB mediated IMD. However, further studies are required to confirm this mechanism.

Zhang et. al. used $1 \mathrm{mg} / \mathrm{kg} \quad \mathrm{CuB}$ through intraperitoneal injection thrice a week against melanoma tumors. They observed about $50 \%$ suppression of tumor growth after 23 days [59]. Kausar et. al. observed that treatment with $1 \mathrm{mg} / \mathrm{kg} \mathrm{CuB}$ every alternate day for 5 weeks reduced the volume of non-small lung carcinoma tumor xenografts by $70 \%$ [60]. Furthermore, as shown by Aribi et. al., CuB suppressed MDA-MB-231 orthotopic tumor volume by $42 \%$ and $55 \%$ at dose of 0.5 and $1 \mathrm{mg} /$ $\mathrm{kg}$ (i.p.) respectively after 36 days of treatment [61]. In agreement to this study, we also observed a $55 \%$ reduction in tumor volumes when $2 \mathrm{mg} / \mathrm{kg} \mathrm{CuB}$ was administered orally every day for 60 days. In addition, in another orthotopic tumor experiment, we employed murine breast cancer cell line 4T-1, which represents late stage aggressive breast carcinoma, and treated the mice with 
$1 \mathrm{mg} / \mathrm{kg} \mathrm{CuB}$ i.p., every third day [62]. After 28 days, the average tumor volume in treated mice was found to be about $39 \%$ reduced as compared to tumors in control mice. Our two different in vivo tumor experiments confirm the anti-breast tumor properties of $\mathrm{CuB}$. The tumors of $\mathrm{CuB}$ treated mice exhibited inhibitions of HER2/integrins signaling, validating our in vitro observations. The two tumor models used in this study displayed significantly different tumor growth kinetics. However, $\mathrm{CuB}$ suppressed the tumor growth in both the models by inhibiting HER2/ integrin signaling.

Taken together, our results indicate inhibition of HER2-integrin signaling as a novel anti-cancer mechanism of $\mathrm{CuB}$ in breast cancer cells. The HER2 inhibition correlates with suppression of ITGA6 and ITGB4, which further lead to inhibition of integrin-mediated cell survival through ILK1 and paxillin. To the best of our knowledge, this is the first report on induction of apoptosis in breast cancer cells through HER2-integrin signaling inhibition.

\section{MATERIALS AND METHODS:}

\section{Ethics Statement:}

Experiments were conducted in accordance with the ethical standards and according to approved protocol by Institutional Animal Care and Use Committee (IACUC).

\section{Cell culture:}

Human breast carcinoma cell lines MDA-MB-231 and MCF-7 were purchased from ATCC and recently authenticated by STR analysis by our core facility. SKBR3 cells were kindly provided by Dr. Terumi KohwiShigematsu (Lawrence Berkeley National Laboratory, Berkeley, CA, USA). These cells were maintained in DMEM supplemented with 10\% FBS and 5\% PSN [10]. The 4T-1 cells were purchased from Perkin Elmers (Santa Clara, CA, USA). These cells were maintained in RPMI 1640 supplemented with 10\% FBS and 5\% PSN. All the cells used in this study were within twenty passages after receipt or resuscitation. The cells were maintained and passaged in culture as described by us previously [63]

MCF-7 is an ER positive cell line with wild type p53 while MDA-MB-231 and SKBR3 are ER negative cells and harbor mutated p53. 4T-1 cells are triple negative and p53 null murine cells representing stage IV metastatic breast cancer.

\section{Cytotoxicity Studies:}

Cells were plated at a density of 2000-3000 cells/ well in 96 well plates and allowed to attach overnight and treated with different concentrations (0-100nM) of Cucurbitacin B (CuB) (Sigma-Aldrich, St. Louis, MO) for various time intervals. The cells were fixed with ice cold $10 \%$ trichloroacetic acid, washed and stained with sulforhodamine B (SRB) dye and the optical density was measured in Tris base solution using plate reader, after washing the dye with $1 \%$ acetic acid solution as described by us previously $[63,64]$.

\section{Annexin-FITC apoptosis assay:}

Apoptosis assay was performed using a kit (BD Biosciences, CA) according to manufacturer's instructions. Approximately, $0.1 \times 10^{6}$ cells were plated in 6-well plate and left overnight for attachment. After treatment for 48 and $72 \mathrm{~h}$ with $0-75 \mathrm{nM} \mathrm{CuB}$, cells were harvested after trypsinization, washed and suspended in binding buffer to have cell density of $1 \times 10^{6} / \mathrm{ml}$. A $5.0 \mu \mathrm{l}$ of Annexin V-FITC and $5 \mu \mathrm{l}$ of propidium iodide (BD Biosciences, San Jose, CA) were added to the $100 \mu$ l of suspension and incubated for additional $20 \mathrm{~min}$ at room temperature in dark. Total sample volume was made up to $200 \mu 1$ with binding buffer. Samples were analyzed by flow cytometer after vortexing (Accuri C6, MI).

\section{Western Blot Analysis:}

Various breast cancer cells were treated with varying concentrations of $\mathrm{CuB}(0,25,50$ and $75 \mathrm{nM}$ except for 4T-1 cells, which were treated with $0,40,80$ and $150 \mathrm{nM}$ ) for 48 or $72 \mathrm{~h}$. The MDA-MB-231 cells were treated with 50nM Q-VD-OPH, a caspase 3 inhibitor (Apoptrol, Enon, $\mathrm{OH}$ ), $1 \mathrm{~h}$ prior to treatment with $\mathrm{CuB}$ and the cells were collected after $48 \mathrm{~h}$. In another experiment, MDA-MB-231 cells were treated with $10 \mathrm{ng} / \mathrm{ml}$ TGF $\beta$ (Peprotech, Rocky Hill, NJ) for 1 h prior to the treatment with $50 \mathrm{nM} \mathrm{CuB}$ for $48 \mathrm{~h}$. Whole cell lysates were prepared using 4\% (w/v) CHAPS buffer while tumor lysates were prepared by homogenizing the tumors in RIPA lysis buffer. Proteins from control and treated samples were subjected to SDS-PAGE and the segregated proteins were transferred to PVDF membrane. The membrane was developed as described by us previously [63, 65, 66]. All antibodies used in the study were purchased from Cell signaling except HER2 (Abcam, Cambridge, MA), ITGB4 (Santacruz Biotechnology, Dallas, TX), TWIST (Santacruz Biotechnology, Dallas, TX), phospho Akt (S473) (Santacruz Biotechnology, Dallas, TX) and Caspase 3 (Santacruz Biotechnology, Dallas, TX).

\section{Immune-precipitation:}

Immune-precipitation was performed as described

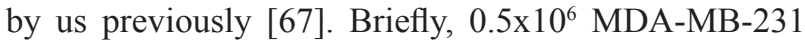


cells were plated in $100 \mathrm{~mm}$ petridish and treated with $10 \mathrm{ng} / \mathrm{ml}$ TGF $\beta$ for $1 \mathrm{~h}$ prior to the treatment with $50 \mathrm{nM}$ $\mathrm{CuB}$. After 48h $\mathrm{CuB}$ treatment, whole cell lysates were prepared using RIPA buffer and immune-precipitated with HER2 antibody (Abcam, Cambridge, MA). Immune complexes were resolved on SDS-PAGE and immuneblotted for ITGA6.

\section{Tumor therapy model:}

Female athymic nude mice (4-6 weeks old) were obtained from Jackson Laboratories (Ban harbor, Maine, USA) and maintained under specific pathogenfree conditions. The use of athymic nude mice and their treatment was approved by the Institutional Animal Care and Use Committee (IACUC), Texas Tech University Health Sciences Center, and the experiments were conducted in strict compliance with the regulations. Mice were given antioxidant-free AIN-76A special diet (TestDiet, Richmond, IN) one week before starting the experiment. Exponentially growing MDA-MB-231 cells were harvested, washed and resuspended in PBS at a density of 50x106 cells per ml with $80 \%$ matrigel (BD Biosciences, San Jose, CA). A suspension of $0.1 \mathrm{~mL}$ containing $5 \times 10^{6}$ cells was injected in the mammary fat pads of the recipient mice. Tumor volumes and animal weights were measured twice a week as described by us previously $[68,69]$. When the tumors reached a size of about $50-80 \mathrm{~mm}^{3}$, mice were randomly segregated into two groups with ten mice in each group. Test group of mice received $2 \mathrm{mg} / \mathrm{kg} \mathrm{CuB}$ in PBS by oral gavage every day till day 60 , whereas control mice received vehicle alone. Mice were sacrificed on day 60 by $\mathrm{CO} 2$ overdose and death was confirmed by cervical dislocation in accordance with IACUC guidelines. The tumors were dissected out aseptically from each mouse, weighed and snap frozen in liquid-nitrogen for western blot analysis.

In another experiment, female BALB/c mice (4-6 weeks old) were obtained from Jackson Laboratories (Ban harbor, Maine, USA) and maintained under controlled humidity and temperature conditions. The use of BALB/c mice and their treatment was approved by the Institutional Animal Care and Use Committee (IACUC), Texas Tech University Health Sciences Center, and the experiments were conducted in strict compliance with the regulations. Exponentially growing 4T-1 cells were harvested, washed and re-suspended in PBS at a density of $1 \times 10^{6}$ cells per $\mathrm{ml}$ with $50 \%$ matrigel. A suspension of $0.1 \mathrm{~mL}$ containing $0.1 \times 10^{6}$ cells was injected in the mammary fat pads of the recipient mice. Tumor volumes and animal weights were measured every alternate day as described by us previously $[68,69]$. When the tumors reached a size of about 30-50 $\mathrm{mm} 3$, mice were randomly segregated into two groups with eight mice in each group. The treatment group of mice received $1 \mathrm{mg} / \mathrm{kg} \mathrm{CuB}$ in PBS by i.p. injection every third day till day 28 . The control mice received vehicle alone. Mice were sacrificed on day 28 by $\mathrm{CO} 2$ overdose and death was confirmed by cervical dislocation in accordance with IACUC guidelines. The tumors were removed aseptically from each mouse, weighed and snap frozen in liquid-nitrogen for further analysis.

\section{Immunohistochemistry:}

The immunohistochemistry (IHC) was performed as previously described by our lab [69]. Paraffin-embedded tumor tissues were sectioned into $5 \mu \mathrm{m}$ thick sections using microtome (Leica Microsystems Inc., Buffalo Grove, IL). The sections were deparaffinized and rehydrated by performing three washes of xylene for 5 minutes each, two washes of $100 \%$ ethanol for 10 minutes followed by two washes of $95 \%$ ethanol for 10 minutes and the sections were given two 5 minute washes in double-distilled water $(\mathrm{dH} 2 \mathrm{O})$. Antigens were unmasked by boiling the sections in $10 \mathrm{mM}$ sodium citrate buffer ( $\mathrm{pH}$ 6.0) followed by incubating the sections at room temperature for about 30 minutes for cooling down. The slides were washed in $\mathrm{dH} 2 \mathrm{O}$ three times for 5 minutes each, then incubated in $3 \%$ hydrogen peroxide solution in methanol for 10 minutes followed by two washes in $\mathrm{dH} 2 \mathrm{O}$ for 5 minutes each. Tumor sections were then washed twice in wash buffer (PBS with $0.1 \%$ Tween-20) for 5 minutes each, blocked in $200 \mu \mathrm{L}$ of blocking solution (5\% goat serum diluted in $1 \%$ bovine serum albumin solution in PBS) for 30 minutes at room temperature, and incubated with anti-HER2 (1:150) (Abcam, Cambridge, MA) or anti-ITGB4 antibody (1:150) (Santacruz Biotechnology, Dallas, TX) overnight at $4^{\circ} \mathrm{C}$. Next day primary antibody was removed and the sections were washed three times in wash buffer for 10 minutes each followed by incubation with Ultravision ONE HRP polymer (Thermofisher scientific, Fremont, CA) for 30 minutes. Subsequently, sections were washed with wash buffer and incubated with DAB Plus chromogen as per the manufacturer's instructions for 15-20 minutes. The sections were counterstained with hematoxylin and dehydrated by incubating in $95 \%$ ethanol followed by two incubations in $100 \%$ ethanol for 5 minutes each and final incubation was done in xylene for 5 minutes. The slides were mounted using Permount (Fisher scientific, Fair Lawn, NJ) and analyzed under a phase-contrast Olympus microscope (Olympus America Inc).

\section{Statistical Analysis:}

Statistical analysis was performed using Prism 6.0 (GraphPad software Inc., San Diego, CA, USA). Results were represented as means $\pm \mathrm{SD}$ or S.E.M with minimum value of $n=3$. Data was analyzed by Student's t-test. Differences were considered statistically significant at $\mathrm{p}<0.05$. 


\section{Conflict of Interest}

The authors declare that they have no competing interests.

\section{Authors' contributions}

PG was responsible for designing the study, performing the experiments and writing the first draft of the manuscript. SKS was responsible for designing the study, analyzing the data and writing the manuscript.

\section{ACKNOWLEDGEMENTS}

This work was supported in part by R01 grant CA129038 (to Sanjay K. Srivastava) awarded by the National Cancer Institute, NIH. Dr. Sanjay K. Srivastava is currently an International Scholar at Kyung Hee University, Seoul, South Korea.

Kind gift of SKBR3 cells by Dr. Terumi KohwiShigematsu (Lawrence Berkeley National Laboratory, Berkeley, CA, USA) is greatly appreciated.

\section{REFERENCES}

1. Siegel, R, Naishadham D and Jemal A. Cancer statistics, 2013. CA: A Cancer Journal for Clinicians. 2013; 63(1):1130.

2. Harris, L, Fritsche H, Mennel R, Norton L, Ravdin P, Taube S, Somerfield MR, Hayes DF, Bast RC, Jr. and American Society of Clinical O. American Society of Clinical Oncology 2007 update of recommendations for the use of tumor markers in breast cancer. Journal of Clinical Oncology. 2007; 25(33):5287-5312.

3. Slamon, DJ, Clark GM, Wong SG, Levin WJ, Ullrich A and McGuire WL. Human breast cancer: correlation of relapse and survival with amplification of the HER-2/neu oncogene. Science. 1987; 235(4785):177-182.

4. King, CR, Kraus MH and Aaronson SA. Amplification of a novel v-erbB-related gene in a human mammary carcinoma. Science. 1985; 229(4717):974-976.

5. Yokota, J, Yamamoto $\mathrm{T}$, Toyoshima K, Terada M, Sugimura T, Battifora $\mathrm{H}$ and Cline MJ. Amplification of c-erbB-2 oncogene in human adenocarcinomas in vivo. Lancet. 1986; 1(8484):765-767.

6. Semba, K, Kamata N, Toyoshima K and Yamamoto T. A $\mathrm{V}$-erbB-related protooncogene, c-erbB-2, is distinct from the c-erbB-1/epidermal growth factor-receptor gene and is amplified in a human salivary gland adenocarcinoma. Proceedings of the National Academy of Sciences. 1985; 82(19):6497-6501.

7. Fukushige, S, Matsubara K, Yoshida M, Sasaki M, Suzuki T, Semba K, Toyoshima K and Yamamoto T. Localization of a novel V-erbB-related gene, c-erbB-2, on human chromosome 17 and its amplification in a gastric cancer cell line. Molecular and Cellular Biology. 1986; 6(3):955-958.

8. Boone, JJ, Bhosle J, Tilby MJ, Hartley JA and Hochhauser D. Involvement of the HER2 pathway in repair of DNA damage produced by chemotherapeutic agents. Molecular Cancer Therapeutics. 2009; 8(11):3015-3023.

9. Kumar, R and Yarmand-Bagheri R. The role of HER2 in angiogenesis. Seminars in Oncology. 2001; 28(5 Suppl 16):27-32.

10. Palmieri, D, Bronder JL, Herring JM, Yoneda T, Weil RJ, Stark AM, Kurek R, Vega-Valle E, Feigenbaum L, Halverson D, Vortmeyer AO, Steinberg SM, Aldape K and Steeg PS. Her-2 overexpression increases the metastatic outgrowth of breast cancer cells in the brain. Cancer Research. 2007; 67(9):4190-4198.

11. Chow, A, Arteaga CL and Wang SE. When tumor suppressor TGFbeta meets the HER2 (ERBB2) oncogene. Journal of Mammary Gland Biology and Neoplasia. 2011; 16(2):81-88.

12. Osborne, CK, Shou J, Massarweh S and Schiff R. Crosstalk between estrogen receptor and growth factor receptor pathways as a cause for endocrine therapy resistance in breast cancer. Clinical Cancer Research. 2005; 11(2 Pt 2):865s-870s.

13. Wu, Y, Shang X, Sarkissyan M, Slamon D and Vadgama JV. FOXO1A is a target for HER2-overexpressing breast tumors. Cancer Research. 2010; 70(13):5475-5485.

14. Belsches-Jablonski, AP, Biscardi JS, Peavy DR, Tice DA, Romney DA and Parsons SJ. Src family kinases and HER2 interactions in human breast cancer cell growth and survival. Oncogene. 2001; 20(12):1465-1475.

15. Kalra, J, Sutherland BW, Stratford AL, Dragowska W, Gelmon KA, Dedhar S, Dunn SE and Bally MB. Suppression of Her2/neu expression through ILK inhibition is regulated by a pathway involving TWIST and YB-1. Oncogene. 2010; 29(48):6343-6356.

16. Wang, SE, Xiang B, Zent R, Quaranta V, Pozzi A and Arteaga CL. Transforming growth factor beta induces clustering of HER2 and integrins by activating Srcfocal adhesion kinase and receptor association to the cytoskeleton. Cancer Research. 2009; 69(2):475-482.

17. Moja, L, Tagliabue L, Balduzzi S, Parmelli E, Pistotti V, Guarneri V and D'Amico R. Trastuzumab containing regimens for early breast cancer. Cochrane Database of Systematic Reviews. 2012; 4:CD006243.

18. Desgrosellier, JS and Cheresh DA. Integrins in cancer: biological implications and therapeutic opportunities. Nature Reviews Cancer. 2010; 10(1):9-22.

19. Millard, M, Odde S and Neamati N. Integrin targeted therapeutics. Theranostics. 2011; 1:154-188.

20. Diaz, LK, Cristofanilli M, Zhou X, Welch KL, Smith TL, Yang Y, Sneige N, Sahin AA and Gilcrease MZ. Beta4 integrin subunit gene expression correlates with tumor size and nuclear grade in early breast cancer. Modern Pathology. 
2005; 18(9):1165-1175.

21. Friedrichs, K, Ruiz P, Franke F, Gille I, Terpe HJ and Imhof BA. High expression level of alpha 6 integrin in human breast carcinoma is correlated with reduced survival. Cancer Research. 1995; 55(4):901-906.

22. Takayama, S, Ishii S, Ikeda T, Masamura S, Doi M and Kitajima M. The relationship between bone metastasis from human breast cancer and integrin alpha(v)beta3 expression. Anticancer Research. 2005; 25(1A):79-83.

23. Liapis, H, Flath A and Kitazawa S. Integrin alpha V beta 3 expression by bone-residing breast cancer metastases. Diagnostic Molecular Pathology. 1996; 5(2):127-135.

24. Sloan, EK, Pouliot N, Stanley KL, Chia J, Moseley JM, Hards DK and Anderson RL. Tumor-specific expression of alphavbeta3 integrin promotes spontaneous metastasis of breast cancer to bone. Breast Cancer Research. 2006; 8(2):R20.

25. Mukhopadhyay, R, Theriault RL and Price JE. Increased levels of alpha 6 integrins are associated with the metastatic phenotype of human breast cancer cells. Clinical \& Experimental Metastasis. 1999; 17(4):325-332.

26. Jones, JL, Royall JE, Critchley DR and Walker RA. Modulation of myoepithelial-associated alpha6beta4 integrin in a breast cancer cell line alters invasive potential. Experimental Cell Research. 1997; 235(2):325-333.

27. Carraway, KL, 3rd and Sweeney C. Co-opted integrin signaling in ErbB2-induced mammary tumor progression. Cancer Cell. 2006; 10(2):93-95.

28. Wang, H, Leavitt L, Ramaswamy $\mathrm{R}$ and Rapraeger AC. Interaction of syndecan and alpha6beta4 integrin cytoplasmic domains: regulation of ErbB2-mediated integrin activation. The Journal of Biological Chemistry. 2010; 285(18):13569-13579.

29. Fan, J, Cai B, Zeng M, Hao Y, Giancotti FG and Fu BM. Integrin beta 4 signaling promotes mammary tumor cell adhesion to brain microvascular endothelium by inducing ErbB2-mediated secretion of VEGF. Annals of Biomedical Engineering. 2011; 39(8):2223-2241.

30. Guo, W, Pylayeva Y, Pepe A, Yoshioka T, Muller WJ, Inghirami $\mathrm{G}$ and Giancotti FG. Beta 4 integrin amplifies ErbB2 signaling to promote mammary tumorigenesis. Cell. 2006; 126(3):489-502.

31. Chen, JC, Chiu MH, Nie RL, Cordell GA and Qiu SX. Cucurbitacins and cucurbitane glycosides: structures and biological activities. Natural Product Reports. 2005; 22(3):386-399.

32. Chan, KT, Meng FY, Li Q, Ho CY, Lam TS, To Y, Lee WH, Li M, Chu KH and Toh M. Cucurbitacin B induces apoptosis and $\mathrm{S}$ phase cell cycle arrest in BEL-7402 human hepatocellular carcinoma cells and is effective via oral administration. Cancer Letters. 2010; 294(1):118-124.

33. Zhang, M, Sun C, Shan X, Yang X, Li-Ling J and Deng Y. Inhibition of pancreatic cancer cell growth by cucurbitacin $\mathrm{B}$ through modulation of signal transducer and activator of transcription 3 signaling. Pancreas. 2010; 39(6):923-929.

34. Jin, HR, Jin X, Dat NT and Lee JJ. Cucurbitacin B suppresses the transactivation activity of RelA/p65. Journal of Cellular Biochemistry. 2011; 112(6):1643-1650.

35. Thoennissen, NH, Iwanski GB, Doan NB, Okamoto R, Lin P, Abbassi S, Song JH, Yin D, Toh M, Xie WD, Said JW and Koeffler HP. Cucurbitacin B induces apoptosis by inhibition of the JAK/STAT pathway and potentiates antiproliferative effects of gemcitabine on pancreatic cancer cells. Cancer Research. 2009; 69(14):5876-5884.

36. Duangmano, S, Dakeng S, Jiratchariyakul W, Suksamrarn A, Smith DR and Patmasiriwat P. Antiproliferative Effects of Cucurbitacin B in Breast Cancer Cells: Down-Regulation of the c-Myc/hTERT/Telomerase Pathway and Obstruction of the Cell Cycle. International Journal of Molecular Sciences. 2010; 11(12):5323-5338.

37. Pastorino, JG, Chen ST, Tafani M, Snyder JW and Farber JL. The overexpression of Bax produces cell death upon induction of the mitochondrial permeability transition. J Biol Chem. 1998; 273(13):7770-7775.

38. Wood, DE and Newcomb EW. Cleavage of Bax enhances its cell death function. Exp Cell Res. 2000; 256(2):375-382.

39. Toyota, H, Yanase N, Yoshimoto T, Moriyama M, Sudo T and Mizuguchi J. Calpain-induced Bax-cleavage product is a more potent inducer of apoptotic cell death than wild-type Bax. Cancer Lett. 2003; 189(2):221-230.

40. Janicke, RU, Sprengart ML, Wati MR and Porter AG. Caspase-3 is required for DNA fragmentation and morphological changes associated with apoptosis. J Biol Chem. 1998; 273(16):9357-9360.

41. Wang, SE, Xiang B, Guix M, Olivares MG, Parker J, Chung $\mathrm{CH}$, Pandiella A and Arteaga CL. Transforming growth factor beta engages TACE and ErbB3 to activate phosphatidylinositol-3 kinase/Akt in ErbB2-overexpressing breast cancer and desensitizes cells to trastuzumab. Molecular and Cellular Biology. 2008; 28(18):5605-5620.

42. Nahta, R. Pharmacological strategies to overcome HER2 cross-talk and Trastuzumab resistance. Current Medicinal Chemistry. 2012; 19(7):1065-1075.

43. Tannin-Spitz, T, Grossman S, Dovrat S, Gottlieb HE and Bergman M. Growth inhibitory activity of cucurbitacin glucosides isolated from Citrullus colocynthis on human breast cancer cells. Biochemical Pharmacology. 2007; 73(1):56-67.

44. Promkan, M, Dakeng S, Chakrabarty S, Bogler O and Patmasiriwat P. The effectiveness of cucurbitacin B in BRCA1 defective breast cancer cells. PLoS One. 2013; 8(2):e55732.

45. Wakimoto, N, Yin D, O'Kelly J, Haritunians T, Karlan B, Said J, Xing H and Koeffler HP. Cucurbitacin B has a potent antiproliferative effect on breast cancer cells in vitro and in vivo. Cancer Science. 2008; 99(9):1793-1797.

46. Bao, L, Haque A, Jackson K, Hazari S, Moroz K, Jetly $\mathrm{R}$ and Dash $\mathrm{S}$. Increased expression of P-glycoprotein 
is associated with doxorubicin chemoresistance in the metastatic 4T1 breast cancer model. American Journal of Pathology. 2011; 178(2):838-852.

47. Biscardi, JS, Maa MC, Tice DA, Cox ME, Leu TH and Parsons SJ. c-Src-mediated phosphorylation of the epidermal growth factor receptor on Tyr845 and Tyr1101 is associated with modulation of receptor function. The Journal of Biological Chemistry. 1999; 274(12):8335-8343.

48. Bouton, AH, Riggins RB and Bruce-Staskal PJ. Functions of the adapter protein Cas: signal convergence and the determination of cellular responses. Oncogene. 2001; 20(44):6448-6458.

49. Glukhova, MA and Streuli CH. How integrins control breast biology. Current Opinion in Cell Biology. 2013; 25(5):633641.

50. Gerson, KD, Shearstone JR, Maddula VS, Seligmann BE and Mercurio AM. Integrin beta4 regulates SPARC protein to promote invasion. The Journal of Biological Chemistry. 2012; 287(13):9835-9844.

51. Draheim, KM, Chen HB, Tao Q, Moore N, Roche M and Lyle S. ARRDC3 suppresses breast cancer progression by negatively regulating integrin beta4. Oncogene. 2010; 29(36):5032-5047.

52. Chen, M, Sinha M, Luxon BA, Bresnick AR and O'Connor KL. Integrin alpha6beta 4 controls the expression of genes associated with cell motility, invasion, and metastasis, including S100A4/metastasin. The Journal of Biological Chemistry. 2009; 284(3):1484-1494.

53. Lu, S, Simin K, Khan A and Mercurio AM. Analysis of integrin beta4 expression in human breast cancer: association with basal-like tumors and prognostic significance. Clinical Cancer Research. 2008; 14(4):10501058.

54. Lu, S, Simin K, Khan A and Mercurio AM. Analysis of integrin beta4 expression in human breast cancer: association with basal-like tumors and prognostic significance. Clin Cancer Res. 2008; 14(4):1050-1058.

55. Schwartz, MA. Integrins, oncogenes, and anchorage independence. J Cell Biol. 1997; 139(3):575-578.

56. Gilcrease, MZ. Integrin signaling in epithelial cells. Cancer Letters. 2007; 247(1):1-25.

57. Schaller, MD, Otey CA, Hildebrand JD and Parsons JT. Focal adhesion kinase and paxillin bind to peptides mimicking beta integrin cytoplasmic domains. J Cell Biol. 1995; 130(5):1181-1187.

58. Hannigan, G, Troussard AA and Dedhar S. Integrin-linked kinase: a cancer therapeutic target unique among its ILK. Nature Reviews Cancer. 2005; 5(1):51-63.

59. Zhang, Y, Ouyang D, Xu L, Ji Y, Zha Q, Cai J and He $\mathrm{X}$. Cucurbitacin B induces rapid depletion of the G-actin pool through reactive oxygen species-dependent actin aggregation in melanoma cells. Acta Biochimica et Biophysica Sinica. 2011; 43(7):556-567.

60. Kausar, H, Munagala R, Bansal SS, Aqil F, Vadhanam MV and Gupta RC. Cucurbitacin B potently suppresses nonsmall-cell lung cancer growth: identification of intracellular thiols as critical targets. Cancer Letters. 2013; 332(1):35-45.

61. Aribi, A, Gery S, Lee DH, Thoennissen NH, Thoennissen GB, Alvarez R, Ho Q, Lee K, Doan NB, Chan KT, Toh M, Said JW and Koeffler HP. The triterpenoid cucurbitacin B augments the antiproliferative activity of chemotherapy in human breast cancer. International Journal of Cancer. 2013; 132(12):2730-2737.

62. Tao, K, Fang M, Alroy J and Sahagian GG. Imagable 4T1 model for the study of late stage breast cancer. BMC Cancer. 2008; 8:228.

63. Gupta, P and Srivastava SK. Antitumor activity of phenethyl isothiocyanate in HER2-positive breast cancer models. BMC Medicine. 2012; 10:80.

64. Gupta, P, Adkins C, Lockman P and Srivastava SK. Metastasis of Breast Tumor Cells to Brain Is Suppressed by Phenethyl Isothiocyanate in a Novel Metastasis Model. PLoS One. 2013; 8(6):e67278.

65. Sahu, RP, Zhang R, Batra S, Shi Y and Srivastava SK. Benzyl isothiocyanate-mediated generation of reactive oxygen species causes cell cycle arrest and induces apoptosis via activation of MAPK in human pancreatic cancer cells. Carcinogenesis. 2009; 30(10):1744-1753.

66. Loganathan, S, Kandala PK, Gupta P and Srivastava SK. Inhibition of EGFR-AKT axis results in the suppression of ovarian tumors in vitro and in preclinical mouse model. PLoS One. 2012; 7(8):e43577.

67. Batra, S, Sahu RP, Kandala PK and Srivastava SK. Benzyl Isothiocyanate-Mediated Inhibition of Histone Deacetylase Leads to NF-\{kappa\}B Turnoff in Human Pancreatic Carcinoma Cells. Molecular Cancer Therapeutics. 2010.

68. Boreddy, SR, Pramanik KC and Srivastava SK. Pancreatic tumor suppression by benzyl isothiocyanate is associated with inhibition of PI3K/AKT/FOXO pathway. Clinical Cancer Research. 2011; 17(7):1784-1795.

69. Sahu, RP and Srivastava SK. The role of STAT-3 in the induction of apoptosis in pancreatic cancer cells by benzyl isothiocyanate. Journal of National Cancer Institute. 2009; 101(3):176-193. 